\title{
BOUNDEDNESS AND CONTINUITY OF MAXIMAL OPERATORS ASSOCIATED TO POLYNOMIAL COMPOUND CURVES ON TRIEBEL-LIZORKIN SPACES
}

\author{
FENG LIU
}

Abstract. In this paper we study the Triebel-Lizorkin space boundedness and continuity of maximal operators related to rough singular integrals associated to polynomial compound curves. We prove that the above operators are bounded and continuous on the inhomogeneous TriebelLizorkin space $F_{p, q}^{\alpha}\left(\mathbb{R}^{n}\right)$ for all $\alpha \in(0,1), p \in[2, \infty)$ and $q \in(2 p /(p+2), \infty)$ under the conditions that the integral kernels are given by $\Omega \in L\left(\log ^{+} L\right)^{1 / 2}\left(\mathrm{~S}^{n-1}\right) \cup\left(\cup_{1<r<\infty} B_{r}^{0,-1 / 2}\left(\mathrm{~S}^{n-1}\right)\right)$. We also establish the boundedness and continuity of the above operators on the inhomogeneous Besov space $B_{p, q}^{\alpha}\left(\mathbb{R}^{n}\right)$ for $\alpha \in(0,1), p \in[2, \infty)$ and $q \in(1, \infty)$. In addition, the corresponding results for maximal operators related to parametric Marcinkiewicz integrals are also considered.

Mathematics subject classification (2010): 42B20, 42B15, 42B25.

Keywords and phrases: Maximal operator, singular integral, Marcinkiewicz integral, Triebel-Lizorkin spaces, Besov spaces.

\section{REFERENCES}

[1] H. M. Al-QAssem, L. C. Cheng AND Y. PAN, Boundedness of rough integral operators on TriebelLizorkin spaces, Publ. Mat. 56, (2012), 261-277.

[2] H. M. Al-QASSEM AND Y. PAN, On certain estimates for Marcinkiewicz integrals and extrapolation, Collect. Math. 60, 2 (2009), 123-145.

[3] H. M. Al-QASSEm, Maximal operators related to block spaces, Kodai Math. J. 28, (2005), 494-510.

[4] A. Al-S alman, Parabolic Marcinkiewicz integrals along surfaces on product domains, Acta Math. Sinica Engl. Ser. 27, 1 (2011), 1-18.

[5] A. Al-S ALmAn, On a class of singular integral operators with rough kernels, Canad. Math. Bull. 49, 1 (2006), 3-10.

[6] A. Al-S Alman, On maximal functions with rough kernels in $L\left(\log ^{+} L\right)^{1 / 2}\left(\mathrm{~S}^{n-1}\right)$, Collect. Math. 56, 1 (2005), 47-56.

[7] A. Al-S ALmAn, Rough maximal functions supported by subvarieties, J. Opera. Theory 59, 2 (2002), 263-275.

[8] A. Al-Salman, A note on parabolic Marcinkiewicz integrals along surfaces, Proc. A. Razmadze Math. Inst. 154, (2010), 21-36.

[9] Y. Chen, Y. Ding AND H. LiU, Rough singular integrals supported on submanifolds, J. Math. Anal. Appl. 368, (2010), 677-691.

[10] J. CHEN AND C. ZHANG, Boundedness of rough singular integral on the Triebel-Lizorkin spaces, J. Math. Anal. Appl. 337, (2008), 1048-1052.

[11] L. CHEN AND H. Lin, A maximal operator related to a class of singular integrals, Illinois J. Math. 34, (1990), 120-126.

[12] R. Fefferman, A note on singular integrsls, Proc. Amer. Math. Soc. 74, 2 (1979), 266-270.

[13] M. FrAZIER, B. JAWERTH AND G. WeISS, Littlewood-Paley theory and the study of function spaces, CBMS Reg. Conf. Ser. vol. 79. Amer. Math. Soc., Providence, RI (1991).

[14] Y. JiAng AND S. LU, $L^{p}$ boundedness of a class of maximal singular integral operators, Acta Math. Sin. (Chin. Ser.), 35, (1992), 63-72. 
[15] S. KORRY, Boundedness of Hardy-Littlewood maximal operator in the framework of Lizorkin-Triebel spaces, Rev. Mat. Complut. 15, 2 (2002), 401-416.

[16] F. Liu, On singular integrals associated to surfaces, Tohoku Math. J. 66, 1 (2014), 1-14.

[17] F. LiU, Integral operators of Marcinkiewicz type on Triebel-Lizorkin spaces, Math. Nachr. 290, 1 (2017), 75-96.

[18] F. LiU, On the Triebel-Lizorkin space boundedness of Marcinkiewicz integrals along compound surfaces, Math. Inequal. Appl. 20, 2 (2017), 515-535.

[19] F. LiU, A note on Marcinkiewicz integrals associated to surfaces of revolution, J. Austral. Math. Soc. 104 (2018), 380-402.

[20] F. LiU, Rough maximal functions supported by subvarieties on Triebel-Lizorkin spaces, Revista de Real Acad. Cien. Exac. Fisicas Natura. Ser. A. Math. 112 (2) (2018), 593-614.

[21] F. LiU, Z. FU, Y. Zheng AND Q. YuAN, A roug Marcinkiewicz integral along smooth curves, J. Nonlinear Sci. Appl. 9, (2016), 4450-4464.

[22] F. LiU AND H. WU, On the regularity of maximal operators supported by submanifolds, J. Math. Anal. Appl. 453, (2017), 144-158.

[23] F. Liu D. Zhang, Parabolic Marcinkiewicz integrals associated to polynomials compound curves and extrapolation, Bull. Korean Math. Soc. 52, 3 (2015), 771-788.

[24] F. LIU, Q. XUE AND K. YABUTA, Rough maximal singular integral and maximal operators supported by subvarieties on Triebel-Lizorkin spaces, Nonlinear Anal. TMA 171, (2018), 41-72.

[25] H. TRIEBel, Theory of Function Spaces, Monogr. Math. vol. 78, Birkhäser Verlag, Basel, 1983.

[26] H. XU, D. FAN AND M. WANG, Some maximal operators related to families of singular integral operators, Acta Math. Sin. (Engl. Ser.) 20, 3 (2004), 441-452.

[27] K. YABUTA, Triebel-Lizorkin space bounddedness of Marcinkiewicz integrals associated to surfaces, Appl. Math. J. Chinese Univ. 30, 4 (2015), 418-446.

[28] C. Zhang And J. ChEn, Boundedness of g-functions on Triebel-Lizorkin spaces, Taiwan. J. Math. 13, (2009), 973-981. 